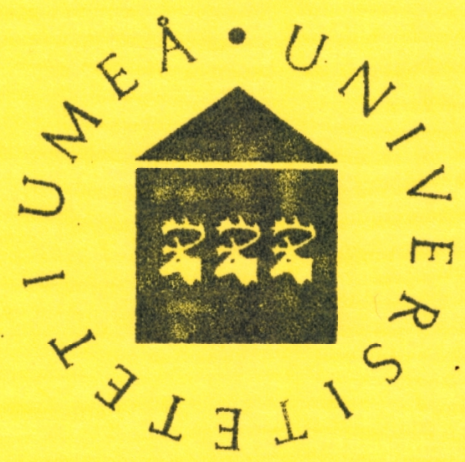

\title{
A MODEL FOR LONG RUN
} FORECASTS OF EMPLOYMENT IN INDUSTRIAL SECTORS

by

Sören Wibe

Umeå Economic Studies No.79 UNIVERBITY OF UMEA 1980 
A MODEL FOR LONG RUN FORECASTS OF EMPLOYMENT

IN INDUSTRIAL SECTORS *

by

Sören Wibe

In this paper I present a simple model for the time path of the demand for labour in a sector in the economy. The model is general in the sense that it can be used for all factors of production but it has special relevance for labour.

The starting point is the identity:

$\mathrm{v} \equiv \frac{\mathrm{v}}{\mathrm{q}} \cdot \mathrm{q}$

where $v=$ the amount of the factor in question and $q=$ total production of the good in the sector. The total model; $v=f(t)$, where $t$ is time, is constructed by combining two models, one for the time development of $v / q$ and one for the time development of $q$. The development of $\mathrm{v} / \mathrm{q}$ is described by a model of the technological progress in the sector and the development of $q$ is described by a model for the time path of total demand.

The central theme of the paper is the introduction of limits both for the technological progress and for total demand. The technological progress is pictured as the successive realisation of a "limited space of possibilities", and the development of total demand as the successive satisfaction of a "limited space of needs" for the good in question.

In the preparation of this paper, I have benefitted from comments by $\AA$ Andersson, $T$ Puu, $K-G$ Löfgren and $P O$ Johansson. Financial support from Länsförsäkringar, Västerbotten and Västerbottens Sparbank are gratefully acknowledged. 
The model is tested on three sectors: Swedish Pulp Industry, Swedish Railway.Traffic and Swedish Telephone Communication, all for the period 1911-1978. I have choosen these sectors to get a great dispersion in the good categories. In this paper I do not, however, test the total model $v=f(t)$ directly, but test separately the two fundamental models (for $\mathrm{v} / \mathrm{q}$ and $\mathrm{q}$ ) and then compare the combination of these results with real observations $(v ; t)$. The reason for this procedure is that $I$, at this stage, want to test the empirical explanation power of the two underlying models before testing the total model directly.

I give a short presentation of the model of technological progress in part II, and an also short presentation of the model for total demand in part III. The total model is analysed in part IV and the empirical results are presented in part $V$. The paper concludes with a summary in part VI.

Let us assume a production function

$q=f\left(v_{1} \ldots v_{n}\right)$

When introducing technological progress we usually introduce a function $A(t)$ and 1 et

$q(t)=A(t) f\left(v_{1} \ldots v_{n}\right)$

in the case of Hicks neutral progress (generalized to the case of $n$ factors of production). $A(t)$ is a function giving the speed of the technological progress, and the usual assumption about the properties of $A(t)$ is

$\frac{\frac{d A}{d t}}{A}=\left(\frac{\dot{A}}{A}\right)=k$

where $k$ is a constant. $A(t)$ then becomes the well known exponential function and the production (with constant amounts of factors) then grows exponentially over time. 
The reason for assuming (3) is seldom explicit outspoken, and it seems probable that this form is chosen foremost because of its simplicity. However, it can be fruitful to use other forms for the function $\Lambda(t)$, since (3) implies that an arbitrary great amount of good can be produced from a given set of inputs. This is not, I think, a realistic picture. On the contrary I think that there exists a definite maximum that can be produced from a given set of factors, even though we assume that the technological knowledge is developed to its maximum. ${ }^{1}$ An alternative assumption is

$\frac{\dot{A}}{A}=C_{1}\left(C_{2}-A(t)\right)$

where $C_{i}$ are constants. This gives for $A(t)$ :

$A(t)=\frac{C_{2}}{I+C_{3} e^{C_{4} t}}$

where $\mathrm{C}_{3}$ and $\mathrm{C}_{4}$ are new constants. $\left(\mathrm{C}_{3}\right.$ a constant of integration and $\mathrm{C}_{4}$ determined from eq (4)).

Assumption (4) is an assumption of a "bounded space" of technological possibilities. It holds that

$\lim A(t)=C_{2}$

$t \rightarrow \infty$

i.e. that there exists an upper limit for $A(t)$.

A short interpretation of the assumption (4) can be given if we write (4) as

$\dot{A}=C_{1} \cdot A(t) \cdot\left(C_{2}-A(t)\right)$

1. This is the same as saying that factor input per unit of output has an under limit. This is most certainly the case for material and energy inputs in most processes. 
The speed of the technological progress (i.e. $\dot{A}$ ) is determined by two factors: $A(t)$ and $C_{2}-A(t)$. The more $A(t)$ grows, the more grows the general knowledge of the process in question. This knowledge, however, forms a base for future growth and the possibilities of new discoveries in the field is assumed to be proportional to this base. There exists, however, a finite space of technological possibilities and the more $A(t)$ grows, the more is this space exhausted. The possibilities of new technical discoveries is then also seen as proportional to the "room of undiscovered possibilities", i.e. C2 - A(t). The result of all this is then the model (4).

The model presented is "technical" in the sense that economic variables don't enter as determinants of the path for $A(t)$. This may, however, not be an unrealistic picture. As well known, many factors influence the rate of technological progress: science, individual inventors, the efforts of individual firms etc. The total outcome of this whole process may well be a time path that is largely independent of the development of prices, something that appears as just "given from above" to the individual firm.

In principle, there is nothing preventing us from using the model (4) whereever we now use the model (3). In fact, it may even be a realistic picture of a whole economy to assume a finite amount of technological possibilities. However, I think that the best application of the model is on separate production processes and specific machines, where the finite technological space can be accurately motivated on technological grounds. This model, or some form of it, is also used in the engineering litterature, then picturing the time development of some technical "figures of merit", e.g. the degree of efficiency of a machine.

In this paper I have used the model on separate production processes. This allows me also to make some rather drastic assumptions on the form of the production function. I assume here that these are of the Leontief type, i.e. of the form:

$Q=\min \left(a_{1} v_{1} \ldots \ldots a_{n} v_{n}\right)$ 
where $a_{i}$ are the fixed coefficients of production. In this production model, technological progress is equal to the lowering of the input coefficients $v_{i} / q\left(=1 / a_{i}\right)$ and if we assume the progress mode1 (4) the time path of the input coefficients takes the form:

$\frac{v_{i}}{q}=c_{1}^{i}+c_{2}^{i} \cdot e^{c_{3}^{i} t}$

where $C_{j}^{i}$ now are new constants, with $C_{1}, C_{2}>0$ and $C_{3}<0$ )

When estimating the input coefficients according to (8), it is often possible to calculate the value of $\mathrm{C}_{1}$ theoretically. $\mathrm{C}_{1}$ is the under limit for the coefficient and this value can often be determined directly from the physical laws that governs the process. This is especially true for the factors material and energy. The consumption of coke per ton iron in a blast furnace is for instance at least about $373 \mathrm{~kg}$, the consumption of wood when making pulp is at least $2 \mathrm{~m}^{3}$ per ton and so on.

In this respect the labour factor presents special problems. It is as a rule impossible to calculate a technologically determined minimum requirement here. This fact should motivate that $C_{1}$ were given the value 0 , but of course this would be an approximation. No process can be fully automated, i.e. the labour input coefficient must always exeed zero. One way of estimating the value for $C_{1}$ in the case of labour could be to start with labour requirement per plant, and try to find this mimimum value. The analysis could then proceed to make an estimation of maximum production per plant. In agriculture for example, the space dimension is vital. One farmer can not run a farm greater than a certain area. This, together with the fact that total production per unit of land has an upper limit, sets the under limit for the labour coefficient. In other cases, for instance when we can not single out individual production units (e.g. railways, tele communications) it might be possible to determine an under limit required to operate the whole sector. The under limit for the input coefficient will then be determined by the eventually existing upper limit for total production in the sector. 
In the empirical part of this paper I have, however, everywhere approximated $C_{1}$ for labour with 0 . It is, I think, a realistic approximation for all three sectors under consideration.

Concerning the model for total demand, I think one has to decide whether to analyze short run developments (i.e. 10-20 years) or long run trends. A suitable model for short run purposes is:

$q(t)=\frac{A_{1}}{1+A_{2} e^{A_{3}} t}$

This model is frequently used in business economics, then picturing the life cycle of a product. The arguments for its use could run as follows:

Let us assume that the overall development of an aconomy creates a demand for a product. From the point of utility, there exists an upper limit for its use, and additional output over this limit will meet no demand. The product can, however, be used by many persons and firms and for a variety of concrete reasons. The more this product is actually used, people and firms recieve information of its properties and potential use, and new possibilities of using it for special purposes are discovered. However, the more the product is used, the more diminishes the potential possibilities and demand begins ultimately to flatten out towards its equilibrium value. The most simple model taking account of all this is (9), a complete analogy to the technical progress model: demand is stimulated by actual use and hampered by the potential possibilities.

For long run trend purposes the model (9) can be used, but $q(t)$ must now be interpreted as demand per capita; and $t$ must be substituted for income per person, $y(t)$. The reason for using this model can be found in extensive empirical research. Many studies have revealed an upper limit for the consumption per person of a special product, i.e. food, cars, TV etc. (See Prais 1954, Wold 1952). Several studies have also revealed that the Engel curve, i.e. the relation between 
income and demand for a product, has a logistic shape. (E.g. Aitchison and Brown 1954). In all, empirical evidence suggests that the model (9), with the alternations made above, is a good statictical description of demand when income per person rises over time.

In this paper I analyze long run trends and for the sake of convenience only I used the model (9) directly, without taking in account the rise in population and the rise in income per person. These approximations are not, however, too drastic. The rise in population was only about $0.5 \%$ per year in the period studied (which was insignificant when compared to the overall rise in total demand). In addition, if the income per person follows a linear curve over time, it does not matter whether we use $t$ or $y(t)$ in eq (9). As a linear curve actually is a good description for the time period, it is not too drastic to substitute $y(t)$ for $t$. One must, however, remember that these approximations are made for the sake of conveniance only.

Combining the models (8) and (9) yields for the time path for a factor of production:

$v(t)=\left(C_{1}+C_{2} e^{C_{3} t}\right)\left(\frac{A_{1}}{1+A_{2} e^{A_{3} t}}\right)$

When analysing the properties of this function $v=f(t)$, I consider two cases: (i) $\mathrm{C}_{1}=0$ (ii) $\mathrm{C}_{1}>0$. These two cases correspond, in general, to labour and "other factors" respectively. As the analysis is very simple mathematically, I just summarize the main results:

(i) $\mathrm{C}_{1}=0$

We have here three cases depending on the relation between $C_{3}$ and $A_{3}$. 
a) $\mathrm{A}_{3}>\mathrm{C}_{3}$

Properties:

(i) f decreases with time

(ii) $\lim v(t)=0$

$t \rightarrow \infty$

$\lim v(t)=\infty$

$t \rightarrow-\infty$

b) $\mathrm{A}_{3}=\mathrm{C}_{3}$

Properties:

(i) f decreases with time

(ii) $\lim v(t)=0$

$\lim _{t \rightarrow-\infty} v(t)=\frac{A_{1} C_{2}}{A_{2}}$

c) $\mathrm{A}_{3}<\mathrm{C}_{3}$

Properties:

(i) $f$ has a bel1-shaped curve over time

(ii) $\lim _{t \rightarrow \infty} v(t)=\lim _{t \rightarrow-\infty} v(t)=0$

(ii) $\mathrm{C}_{1}>0$

a) $\mathrm{A}_{3}>\mathrm{C}_{3}$

Properties:

(i) f initially falls with time, reaches its minimum, rises and approaches $\mathrm{A}_{1} \mathrm{C}_{1}$ asymtotically from below

(ii) $\lim v(t)=\infty$

$t \rightarrow-\infty$

$\lim _{t \rightarrow \infty} v(t)=A_{1} C_{1}$

b) $\mathrm{A}_{3}=\mathrm{C}_{3}$

Properties:

(i) I has a logistic curve, rising steadily with time but with decreasing growth rate

(ii) $\lim v(t)=0$

$t \rightarrow-\infty$

$\lim _{t \rightarrow \infty} v(t)=A_{1} C_{1}$ 
c) $\mathrm{A}_{3}<\mathrm{C}_{3}$

Properties:

(i) $f$ raises towards a maximum point, falls, and approaches $\mathrm{A}_{1} \mathrm{C}_{1}$ asymtotically from above

(ii) $\lim v(t)=0$

$t \rightarrow-\infty$

$\lim _{t \rightarrow \infty} v(t)=A_{1} C_{1}$

$t \rightarrow \infty$

$\checkmark \quad$ EMPIRICAL RESULTS

The total model (10) can be used for a direct statistical estimation by regression $v$ with $t$. In this paper $I$ have, however, estimated the two fundamental models separately and then compared the estimated values $(v ; t)$ from these with actual observations.

The factor I have used is labour. In all three cases $I$ have assumed that the theoretical minimum value for the input coefficient is 0 . I obtained data for labour input by dividing total labour input in the sector with total production for each year of observation.

The sectors choosen are (i) Swedish Pulp Industry. Production is here measured as the total production of dry pulp in tons. (ii) Swedish Railway Traffic where I measure production as axle-kilometres per year. (iii) Swedish Telephone Communication where I measure production in numbers of periods spoken during the year. (A period is a 3 minutes long telephone call). 
In the table below I give the results for the technological progress model:

Table 1 Results from least-square regression with the mode1 $v / q=C_{2} e^{C_{3} t}$, where $v / q=1$ labour hours per unit of output. $I=$ Swedish Pulp Industry, II = Swedish Railway Traffic, III = Swedish Telephone Communication. Yearly observations every 3:rd year 1911-1978.

$\begin{array}{llcccc} & & \mathrm{C}_{2} & \mathrm{C}_{3} & \mathrm{r}^{2} & \mathrm{DW} \\ \text { I }(\mathrm{hrs} / \text { ton }) & 56.94 & -0.038 & 0.90 & 0.37 \\ \text { II }(\text { hrs/axle-km) } & 0.106 & -0.022 & 0.89 & 0.78 \\ \text { III (hrs/period) } & 0.045 & -0.030 & 0.92 & 0.36\end{array}$

(A11 estimated $C_{i}$ significant on $99 \%$ level)

As can be seen from the values of $r^{2}$, the estimated curve fits well with observations. The Durbin-Watson values are, however, very low, indicating strong correlation in the error terms. However, considering the long time period involved here, this result is not surprising. Technological progress often follows "long vaves" and was for instance, considerably slower during the periods between the two world wars than under the period after the 2:nd war. However, the result emphasize that we must interpret the curve as a long-run curve and not as a curve that can predict what will happen year from year. 
V:2 Results for growth of total demand and production

In the tab1e below I give the estimates for the demand model:

Table 2 Result from least square regression with the model $q=\frac{A_{1}}{1+A_{2} e^{A_{3} t}}$ where $q=$ number of produced units

(per year). Sector $I=$ Swedish Pulp Industry, $I I=$ Swedish Railway Traffic. III = Swedish Telephone Communication. Data based on yearly observation each 3:rd year 1911-1978.

\begin{tabular}{llrrl} 
& \multicolumn{1}{c}{$\mathrm{A}_{1}$} & \multicolumn{1}{c}{$\mathrm{A}_{2}$} & \multicolumn{1}{l}{$\mathrm{A}_{3}$} \\
I $\quad\left(\right.$ Tons $\left.\cdot 10^{6}\right)$ & 12.5 & 26.0 & -0.0502 \\
II (Axlekm $\left.\cdot 10^{6}\right)$ & 4704.2 & 4.5 & -0.0485 \\
III (Periods $\left.\cdot 10^{6}\right)$ & 53796.0 & 175.4 & -0.0598
\end{tabular}

(A11 $\mathrm{A}_{\mathrm{i}}$ significant on $99 \%$ 1eve1)

The object function can not be put on a linear form, and ordinary regression programs can therefore not be used. The special data program used does not give the values of the regression coefficient or DurbinWatson, so in order to give the reader an apprehension of the goodness of the curve fit, I have drawn figures showing the estimated curve together with the observations. These curves are shown in figures la, $b$, c. As can be seen from these figures, the curve fit are fairly good. Especially for sector I and II however, one can easily see that the deviations are systematically spread around the curve, indicating a low DW value.

Something must be said regarding the estimation of these logistic curves. The resulting curve is S-shaped. A reliable estimate of the curve requieres observations along all its shape, otherwise the estimates of the long run equilibrium value (i.e. $A_{1}$ ) will be extremely uncertain. Usually however, observations above the point of inflextion of the curve are very rare. This is so because the time period just passed, i.e. the 50'ies and 60'ies, was a period of rapid growth in almost 
all industrial sectors. In this special case, the estimations regarding railway traffic can be regarded as fairely accurate. The long run equlibrium value ( 4.7 billion axlekilometres per year) is in accordance with the long run forecasts of the industry. Turning to tele communications however, the estimates are extremely uncertain due to the rapid growth of production in the last two decades. The result, 54 billion periods, must therefore be wieved with a good proportion of scepticism. (Current production is about 20 billion periods). Regarding pulp, the problems were even greater. Initially I obtained totally unrealistic results, namely 35 million tons, an amount that would have required raw material amounting to three times the total growths of the forests in Sweden. Instead of adding a production constraint, I then added just one data - 10 million tons in the year of 2000. This figure was drawn from one long time forecast for the industry. The obtained valve of the equlibrium production, 12.5 million tonnes, is accordingly realistic only if the referred long run forecast is. The method adopted, i.e. combining statistical analysis with information of other kind, do however seem reasonable in the type of analysis here conducted.

\section{$V: 3 \quad$ Results for the total model}

If the estimates in $\mathrm{V}: 1$ and $\mathrm{V}: 2$ are combined, one obtains an estimate for the time path of total employment in the sectors. (Measured in hours worked). I have finally compared this curve with the direct observations. The results can be found in figures $2 a, b, c$.

In figure $2 a$, the result for the pulp industry is depicted. As can be seen, both the estimated curve and the observations has a bell shaped form. Maximum for the curve seems to be fairely good placed in time when compared with real observations, i.e. around 1950. However, the curve seems to be displayed downward and somewhat to wide when compared to actual observations. It seems that a direct estimation $v$ against $t$ (with the model (10)) should be able to give a better fit.

The results for railway traffic is depicted in figure $2 b$. As can be seen the deviations are fairely large, but as a long run trend curve, 
the estimates seem "probable". The maximum for the curve, however, is around 1940, while maximum for the observations seems to be close to 1960 .

The result for telephone communication, finally, is shown in 2c. The observations seems here to fit well with the curve, especially up to 1960. According to observations, however, it seems like the maximum in employment already has been reached, as the values for the period 1960-1980 almost the same. According to the curve, however, maximum should occur around 1990, and at a value about $15 \%$ higher than the largest observations.

In this paper I have presented a model for the time path of factors of production, especially labour, in a sector of the economy. The model combines a theory of technological progress with a model of the development of total demand and production for the product. The model is used for evaluting a long run trend curve for labour employment in different sectors.

The empirical results points to a good fit for the model of technological progress. In each case, however, the Durbin-Watson statistics were relatively low, indicating systematic errors in the functional form. This result can be explained by the long character of the estimates. A compairson between the actual values of labour employment and the values predicted by the curve stressed this point. The deviations were large, but as a long run trend curve, the results were not unrealistic. The model presented could therefore be used as a convenient statistical tool in analysing the long run development of factors of production in industrial sectors. 
$-14-$

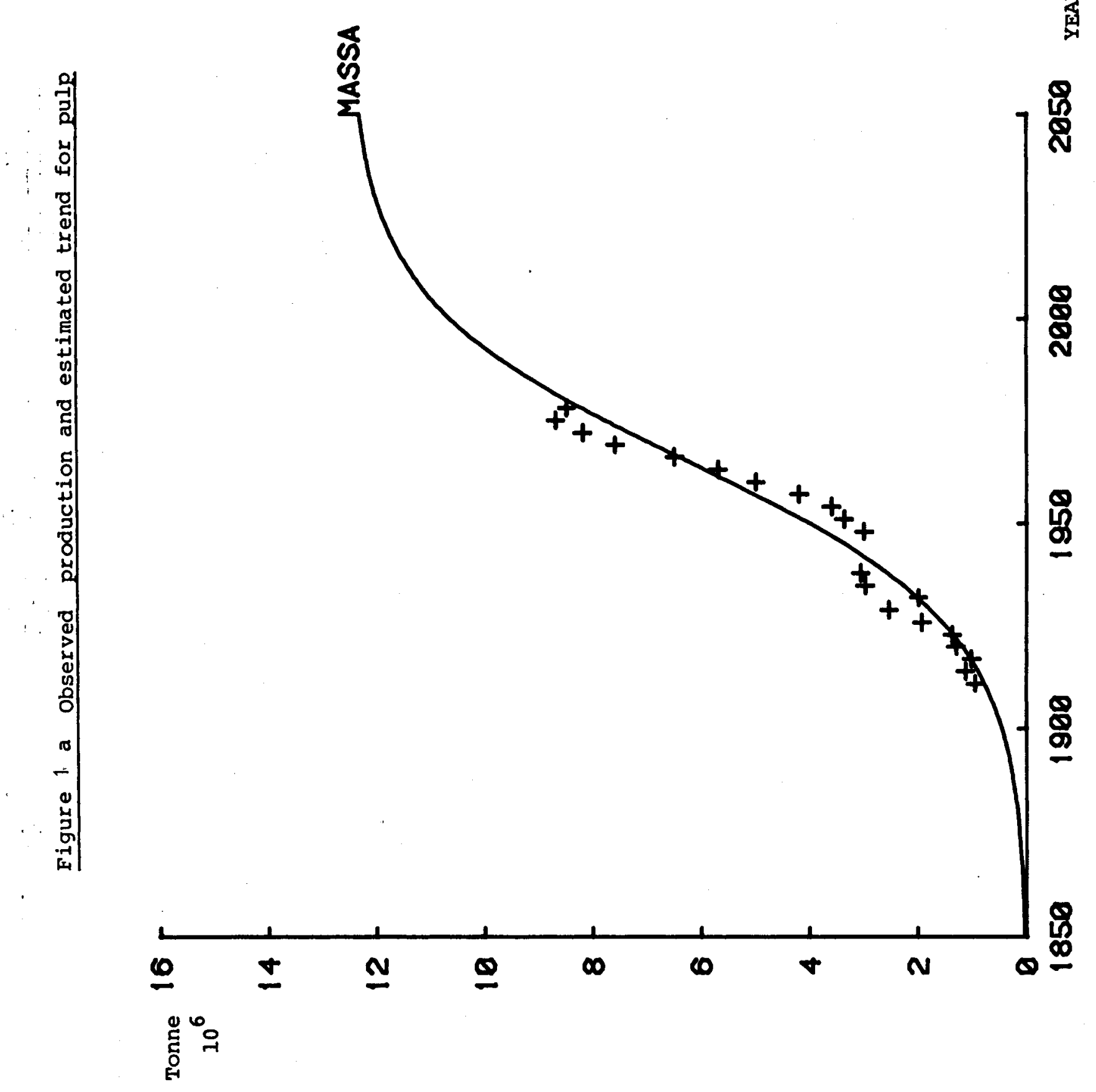


0)

䍃

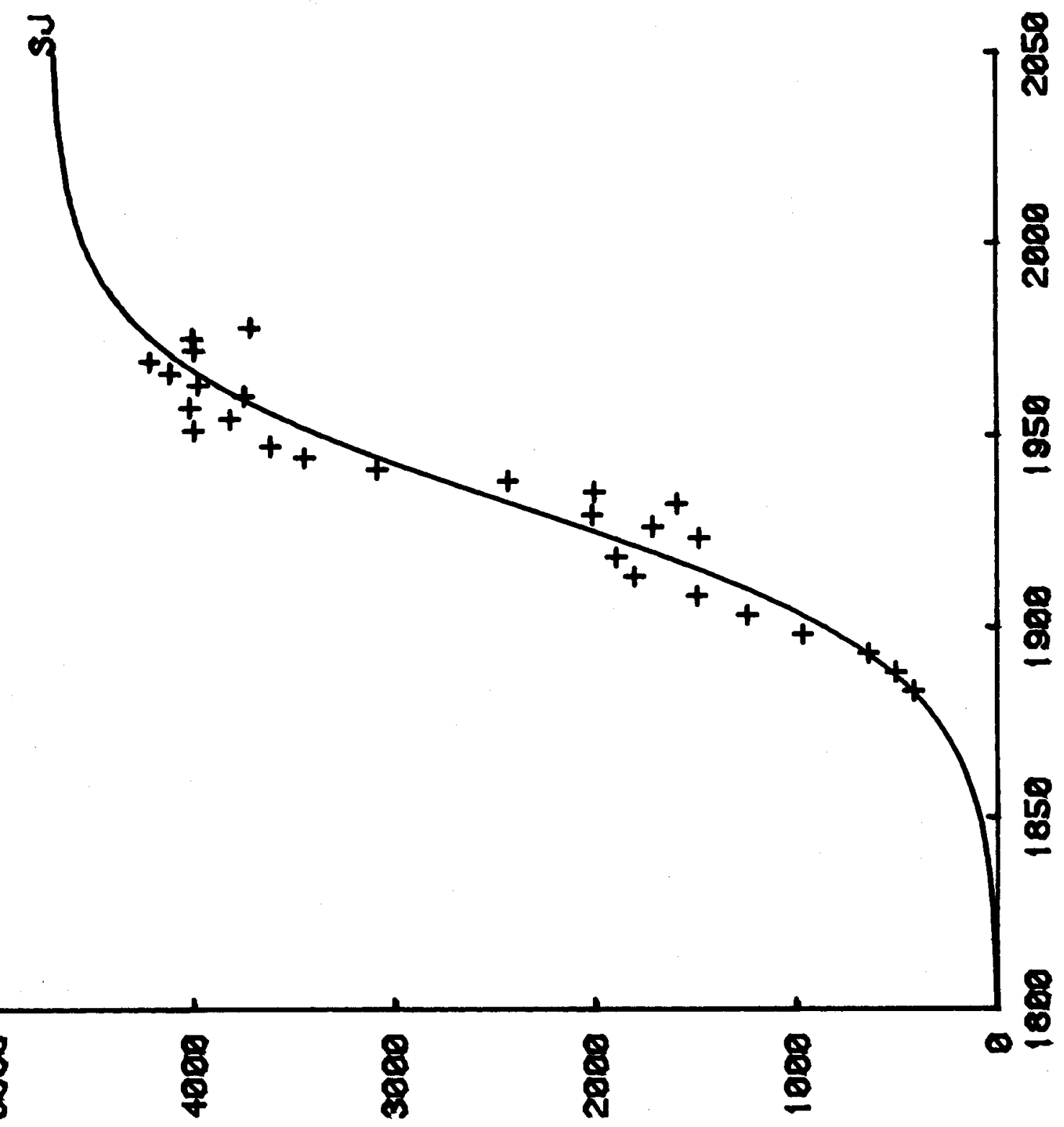

岳 0 


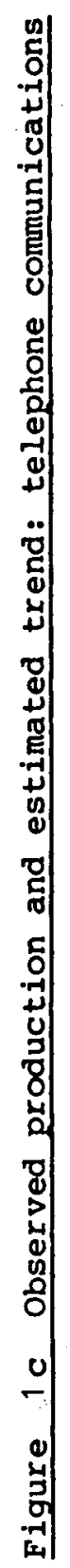

产

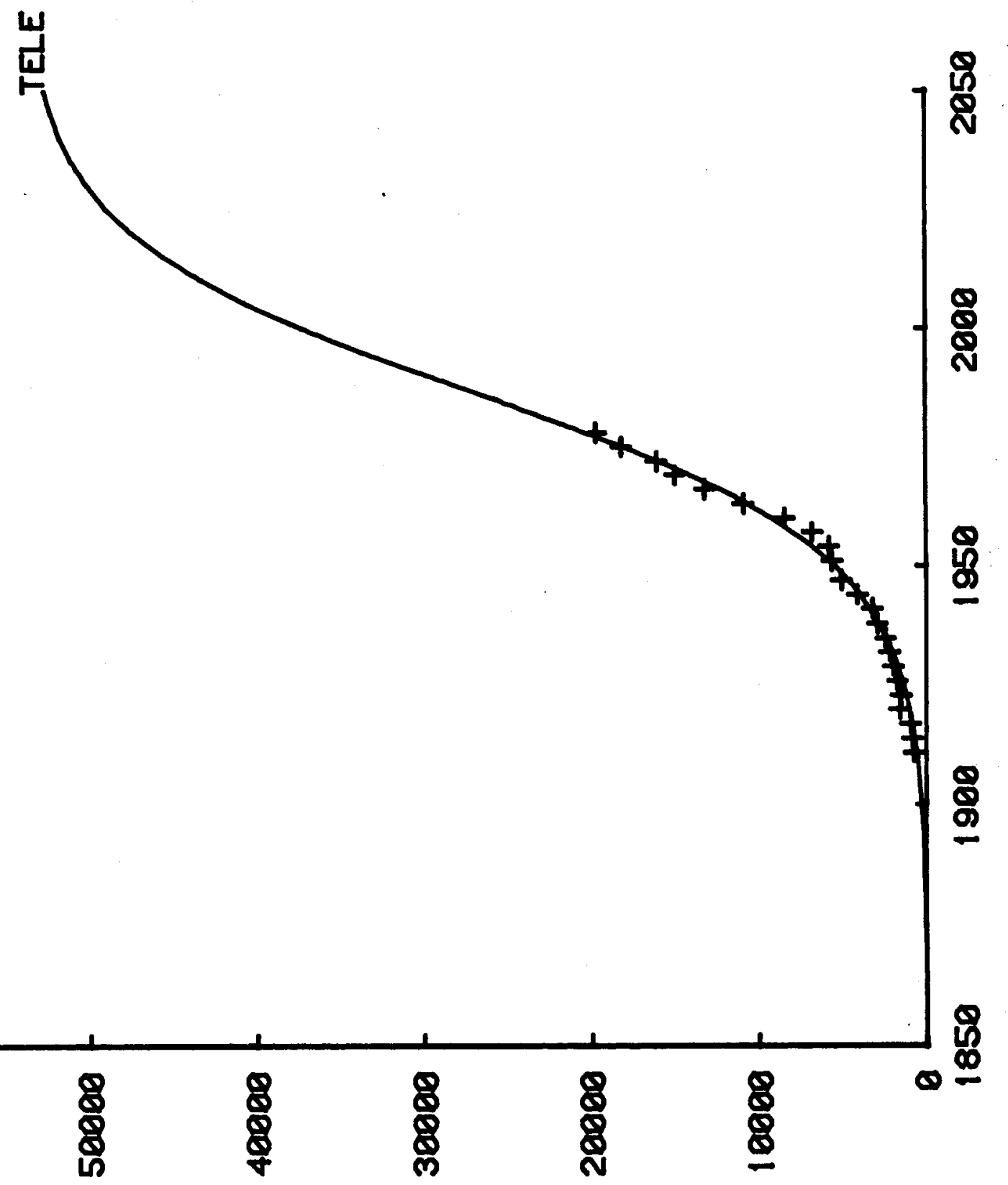

䏛 


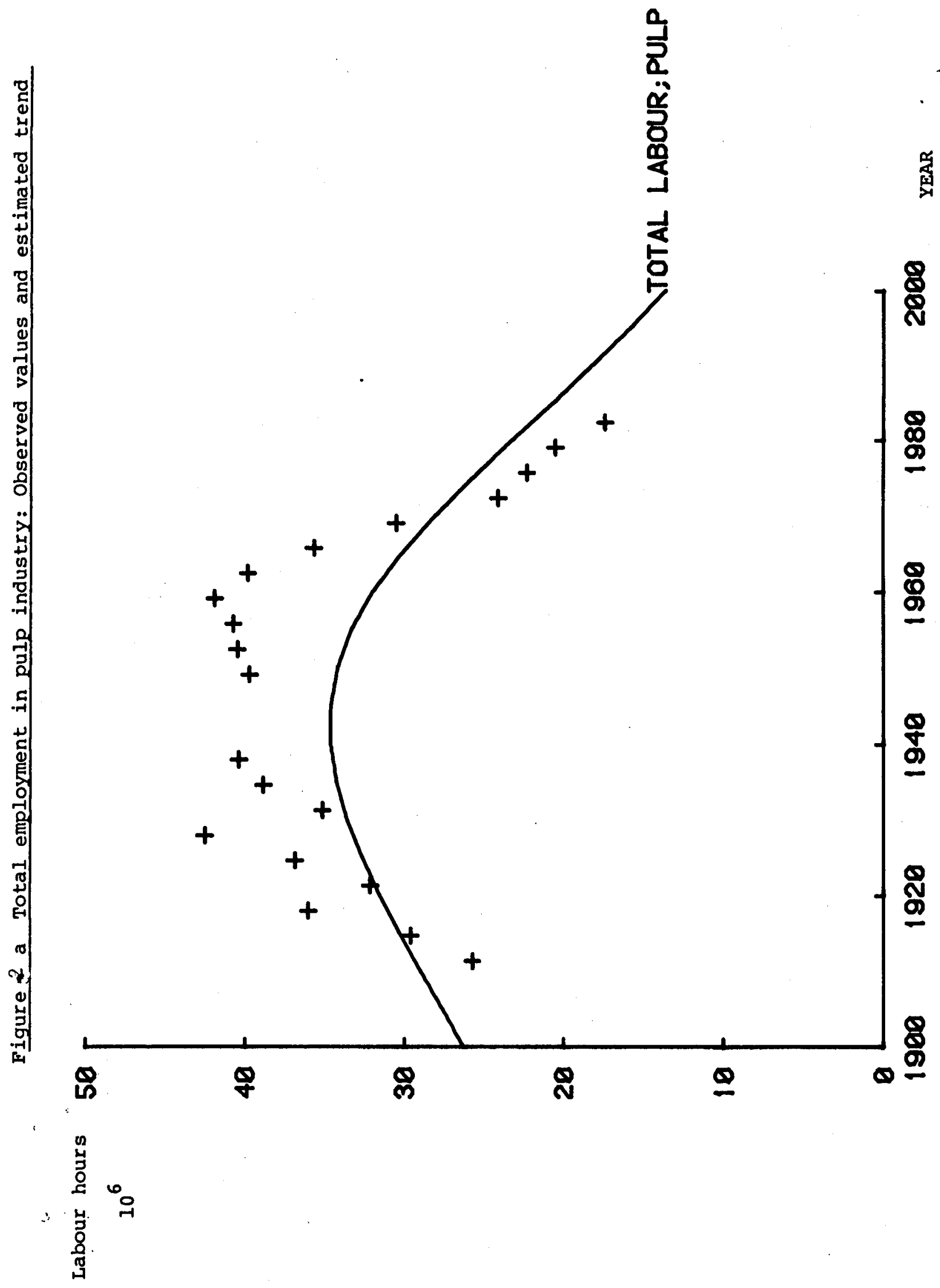


垈

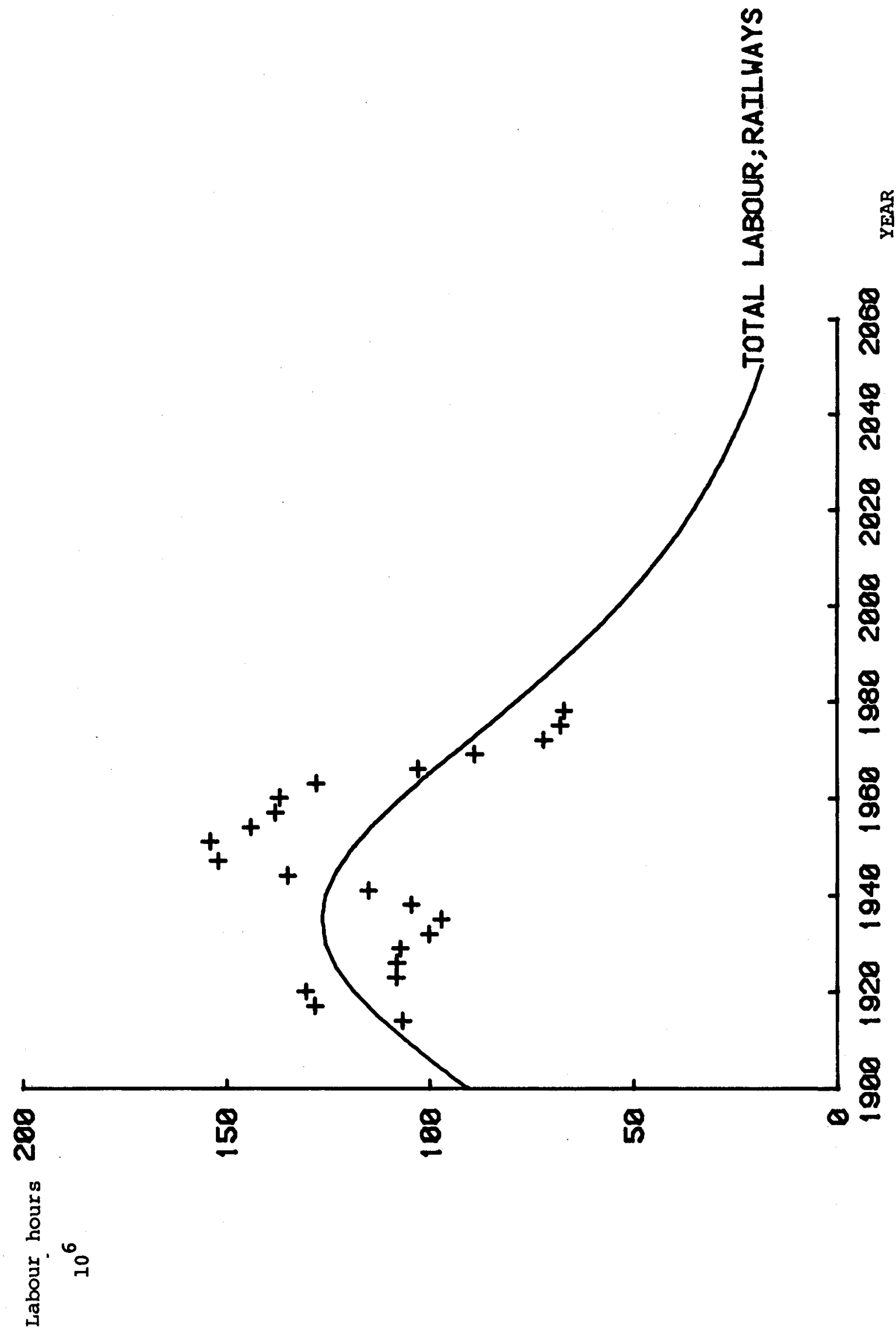



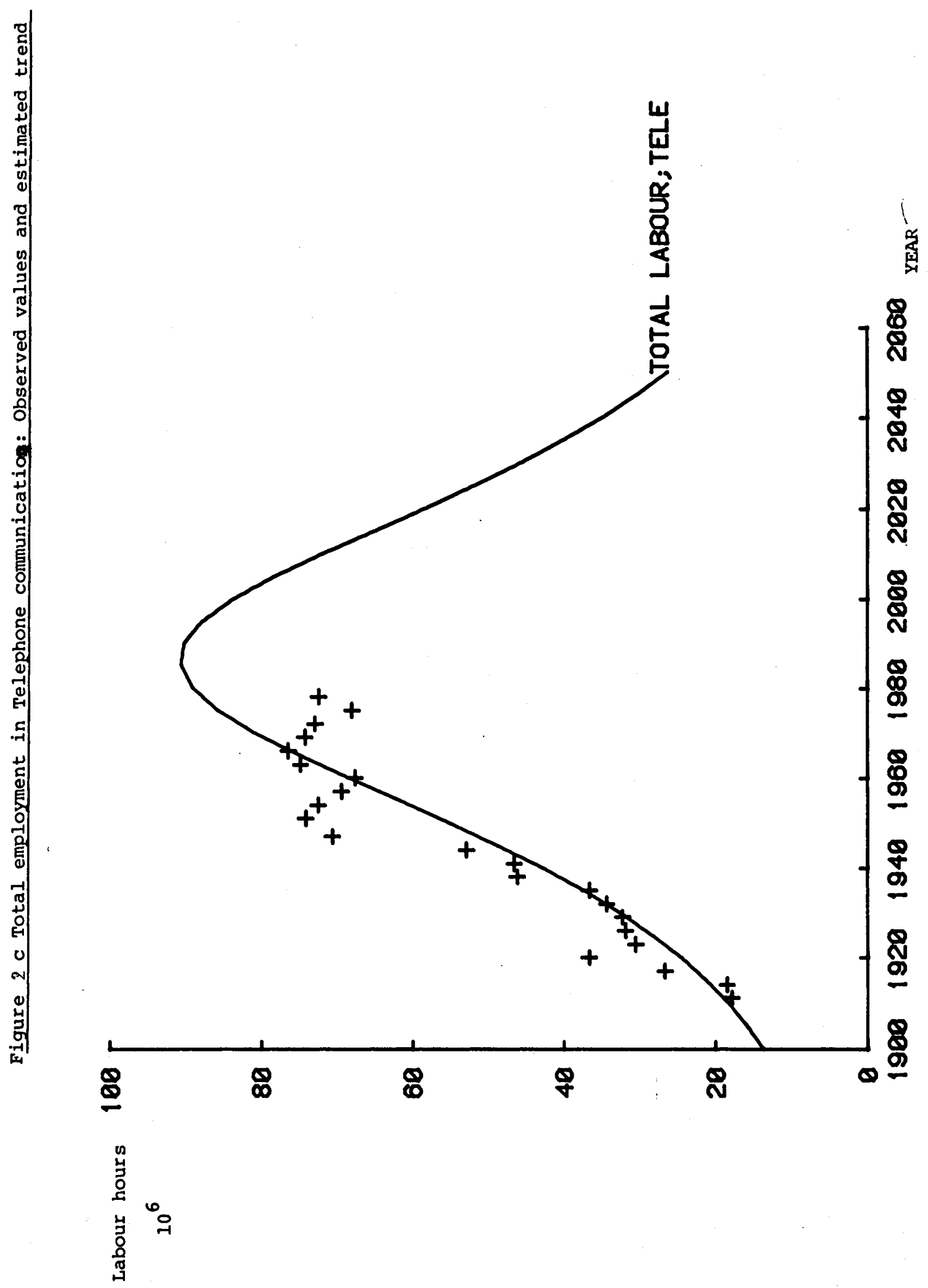


\section{REFERENCES}

Aitchinson, I \&

"A Synthesis of Enge1 Curve Theory", Review

Brown, I A C (1954)

of Economi Studies, 22

Prais, S I (1954)

Non-1inear estimates of the Engel Curve, Review of Economic Studies, 20

Wibe, $\mathrm{S}$

A Model for Technological Progress, Umeå Economic Studies, 1980

Wold, H (1952)

Demand Analysis, Stockholm 